\title{
Türkiye’de Petrol Fiyatlarından Enflasyona Asimetrik ve Doğrusal Olmayan Geçişkenlik
}

\author{
Erkan ÖZATA*
}

öz

Petrol fiyatlarındaki dalgalanmaların önemli ekonomik sonuçları olduğundan akademisyenler ve politika yapıcılar tarafından sıkça araştırılan konuların başında gelmektedir. Petrol fiyatlarındaki artışlar petrol ihraç eden ülkeler için iyi olsa da, Türkiye gibi Petrol yoksunu ve enerji ihtiyacının büyük bölümünü petrol ithal ederek karşılayan ülkeler için kötüdür. Bu alandaki kapsamlı araştırmalar, küresel ham petrol fiyatlarının yerel enflasyon üzerindeki etkisinin çok net olmadığını göstermektedir. Bu çalıșmada Genişletilmiş Phillips eğrisi yaklaşımına dayanarak, doğrusal ve doğrusal olmayan ARDL yöntemleriyle dünya petrol fiyatlarındaki değişimlerin Türkiye'de tüketici ve üretici fiyatları üzerindeki asimetrik etkisi incelenmektedir. Elde edilen sonuçlara göre petrol fiyatlarındaki dalgalanmaların tüketici ve üretici fiyatları üzerindeki etkisi uzun dönemde asimetrikken, kısa dönemde ise simetriktir. Dünya petrol fiyatlarındaki \%100'lük bir artış sonucunda yurtiçi tüketici fiyat endeksi (CPI) \%13,05 üretici fiyat endeksi (PPI) \%14,7 artarken, petrol fiyatlarındaki \%100'lük bir azalış tüketici fiyat endeksini \%11,27, üretici fiyat endeksini $\% 7,24$ azaltmaktadır.

Anahtar Kelimeler: Ham Petrol Fiyatları, Asimetrik Geçişkenlik, Enflasyon, NARDL

JEL Sınıflandırması: C51, E31, Q41

\section{Asymmetric and Nonlinear Pass-Through of Global Crude Oil Price to Inflation in Turkey}

\begin{abstract}
Since the fluctuations in oil prices have important economic consequences, it is one of the most frequently investigated topics by scholars and policymakers. Although increase in oil prices is good for oil exporting countries, it is bad for countries like Turkey who meet energy needs by importing crude oil. The effect of global crude oil prices on domestic inflation is not very clear. In this study, based on the augmented Phillips curve framework, linear and nonlinear ARDL methods are used to examine the asymmetric effects of oil price fluctuations on consumer and producer prices in Turkey. According to the empirical results, the effects of fluctuations in oil prices on consumer and producer prices are asymmetrical in the long run and symmetrical in the short run. A \%100 increase in oil price increases CPI by \%13,05 and PPI by \%14,7. A \%100 decrease in oil price decrease CPI by $\% 11,27$ and PPI by $\% 7,24$.
\end{abstract}

Keywords: Crude Oil Prices, Asymmetric Pass-through, Inflation, NARDL

JEL Classification: C51, E31, Q41

Araştırma Makalesi - Geliş Tarihi / Received: 01.10.2018 Kabul Tarihi / Accepted: 23.10.2018

\footnotetext{
* Doç. Dr., Anadolu Üniversitesi, İktisadi ve İdari Bilimler Fakültesi, İktisat Bölümü, eozata @ anadolu.edu.tr, ORCID: 0000-0001-6468-4040
} 


\section{GİRIŞ}

Günümüzde petrol ve yan ürünleri tüm ülke ekonomileri açısından kritik öneme sahip enerji kaynaklarından birisidir. Ekonomilerin temel girdilerinden olan petrol fiyatlarının artması, petrol ithalatçısı ülkelerde girdi maliyetlerinin artmasına ve ödemeler dengesinin bozulmasına neden olmaktadır. Maliyetlerin artması ile birlikte enflasyon oranları artar ve milli gelir büyümesi yavaşlar. Diğer taraftan petrol üreticisi ve ihracatçısı ülkeler ise gelirlerini arttıracaklarından petrol fiyatlarındaki artıştan olumlu etkilenerek büyüme oranlarını arttırabilirler. Petrol fiyatlarının enflasyona etkisi aslında doğrudan bir etki değildir. Bu etkinin önemi akaryakıt ürünlerinden alınan verginin yüksek olmasından kaynaklanmaktadır. Özellikle ekonomik durgunluk ve yüksek işsizlik dönemlerinde hükümetler akaryakıt üzerinden alınan vergileri düşürerek petrol fiyatlarındaki artışların yurtiçi enflasyona yansımasını engelleyebilmektedir.

2017 yılı dünya ispatlanmış petrol rezervi 1.696,6 milyar varil olarak tespit edilmiştir. Petrol rezervinin 807,7 milyar varili $(\% 47,6)$ Orta Doğu ülkelerinde, 330,1 milyar varili $(\% 19,5)$ Güney ve Orta Amerika ülkelerinde, 226,1 milyar varili Kuzey Amerika ülkelerinde $(\% 13,3)$ bulunmaktadır. 2017 y1lında dünya petrol üretimi 97,4 milyon varil/gün'e ulaşmıştır. Birincil enerji kaynakları arasında stratejik konuma sahip olan ham petrol 2017 y1lı itibarıyla dünya enerji talebinin \%33,7'sini karşılamıştır. Geçtiğimiz on yıl içerisinde Türkiye ekonomisi büyümüş, petrol ve yan ürünlerinin tüketimi de artmıştır. Sınırlı yurtiçi rezervleri ile Türkiye neredeyse tüm petrol kaynaklarını ithal etmektedir. Enerji Piyasası Düzenleme Kurumu (EPDK) verilerine göre Türkiye'nin petrol ürünleri ithalatı 2017 y1lında bir önceki yıla göre \%6,43 artarak 42 milyon 653 bin ton olarak gerçekleşmiştir. En fazla ithalat yapılan ülkeler ise İran, Rusya ve Irak'tır. Petrol ithalatındaki en büyük kalem ise ham petrol ithalatıdır.

Petrol fiyatlarındaki değişikliklerin yurtiçi fiyatlar üzerindeki etkileri doğrudan ve dolaylı olmak üzere iki şekilde gerçekleşmektedir. Doğrudan ilk etkiler dünya petrol fiyatlarının artması sonucunda doğrudan tüketicilerin kullandıkları akaryakıt ve petrol yan ürünlerinin fiyatlarının artması ile gerçekleşir. Dolaylı ilk etkiler ise petrol fiyatlarındaki değişimin üretim maliyetlerini arttırması sonucunda tüketicilerin kullandıkları mal ve hizmetlerin fiyatlarının değişmesi ile gerçekleşir. Örneğin petrolün önemli bir girdi olduğu kimyasal maddeler ve ulaşım hizmetlerinin fiyatları petrol fiyatlarındaki artıştan etkilenecektir. Petrol fiyatlarındaki bir defaya mahsus değişiklikler ister doğrudan, isterse dolaylı olsun, sadece fiyat düzeyinde bir artı̧̧ yaratacak ancak kalıcı enflasyonist etkiler ortaya çıkartmayacaktır (ECB, 2010). İkinci tur etkiler ise fiyat şokuna ücretlerin ve fiyat belirleyicilerinin tepkilerini göstermesi sonucunda ortaya çıkar. Geçmiş dönem enflasyon şoklarının neden olduğu reel gelir kayıpları ekonomik birimlerin enflasyon beklentilerini etkileyerek daha yüksek fiyat ve ücret belirleme davranışına neden olur. $\mathrm{Bu}$ şekilde geçici bir şok kalıcı hale gelerek ortadan kaldırmak daha maliyetli hale gelmiş olur. Petrol fiyatlarındaki değişimlerin ikinci tur etkilerinin olabilmesi ekonomik konjonktürün durumu, mal ve hizmet piyasasının esnekliği, enflasyon beklentilerinin nasıl oluştuğu, Merkez Bankasının güvenilirliği gibi birçok değişik faktöre bağlıdır. Petrol fiyatlarındaki değişimin en fazla ve en hızlı etkisi ise doğrudan tüketicilerin kullandıkları petrol ve yan ürünlerinin fiyatlarındaki değişikliklerde görülür. Petrol ithalatçısı bir ülke olan Türkiye'nin bu ilk etkileri ortadan kaldırmak konusunda yapabileceği çok fazla şey bulunmamaktadır. Ancak inandırıcı bir para politikası ile enflasyon beklentilerini iyi yönetip petrol fiyatlarındaki artışların enflasyona geçişlerini orta ve uzun vadede azaltabilir.

Petrol fiyatlarının görünümü arz ve talep koşullarındaki sürekli değişikliklerden dolayı belirsizlikler içermektedir. Arz tarafında, yaşanan finansal krizler ve sonrasında ortaya çıkan durgunluk petrol üretim kapasitesini arttıracak yatırımların yapılmasını engellemiştir. Ayrıca önemli bir enerji kaynağ 1 olan petrolün kalan rezervleri konusunda ciddi belirsizlikler bulunmaktadır. Ancak teknolojik gelişmeler ve şeyl gazı gibi alternatif enerji kaynaklarının keşfi 
ile petrol arzının bugün tahmin edilenden daha fazla olacağı söylenebilir. Talep tarafında ise küresel ekonomik kriz sonrasında gelişmiş ve gelişmekte olan ülkelerde büyüme oranları arttıkça petrol talebi de artmıştır. Karbon fiyatlaması, alternatif yenilenebilir enerji kaynaklarının teşvik edilmesi ve enerji verimliliği gibi çevreci politikalar ise petrol talebini azaltabilir. Ancak üzerinde fikir birliğine varılan en olası senaryoya göre petrolde talep fazlası olacak ve petrol fiyatlarındaki yukarı yönlü baskı orta vadede devam edecektir.

Avrupa Brent petrolün varil başına fiyatı inceleme dönemi olan 2003-2018 döneminde ciddi dalgalanmalar göstermiş̧tir. 2003 yılının başında 28 Dolar civarında olan petrol fiyatı, 2008 yılının ikinci çeyreğinde 138 Dolara kadar çıkmış, sonraki dönemde tekrar azalmıştır. 2010-2014 döneminde 100 Doların üzerinde seyreden petrol fiyatları daha sonra azalarak 40-60 Dolar bandında seyretmiştir. 2018 yılında ise artış yönünde bir eğilime girerek 77 Dolar civarında seyrini sürdürmektedir. Tüketici ve yurtiçi üretici fiyat endeksleri ise aynı dönemde birlikte hareket ederek artış yönünde bir eğilim sergilemiştir. Ekonomik konjonktürün durumuna göre bazen tüketici fiyat endeksi yukarıda iken bazen de üretici fiyat endeksi üste geçmektedir.

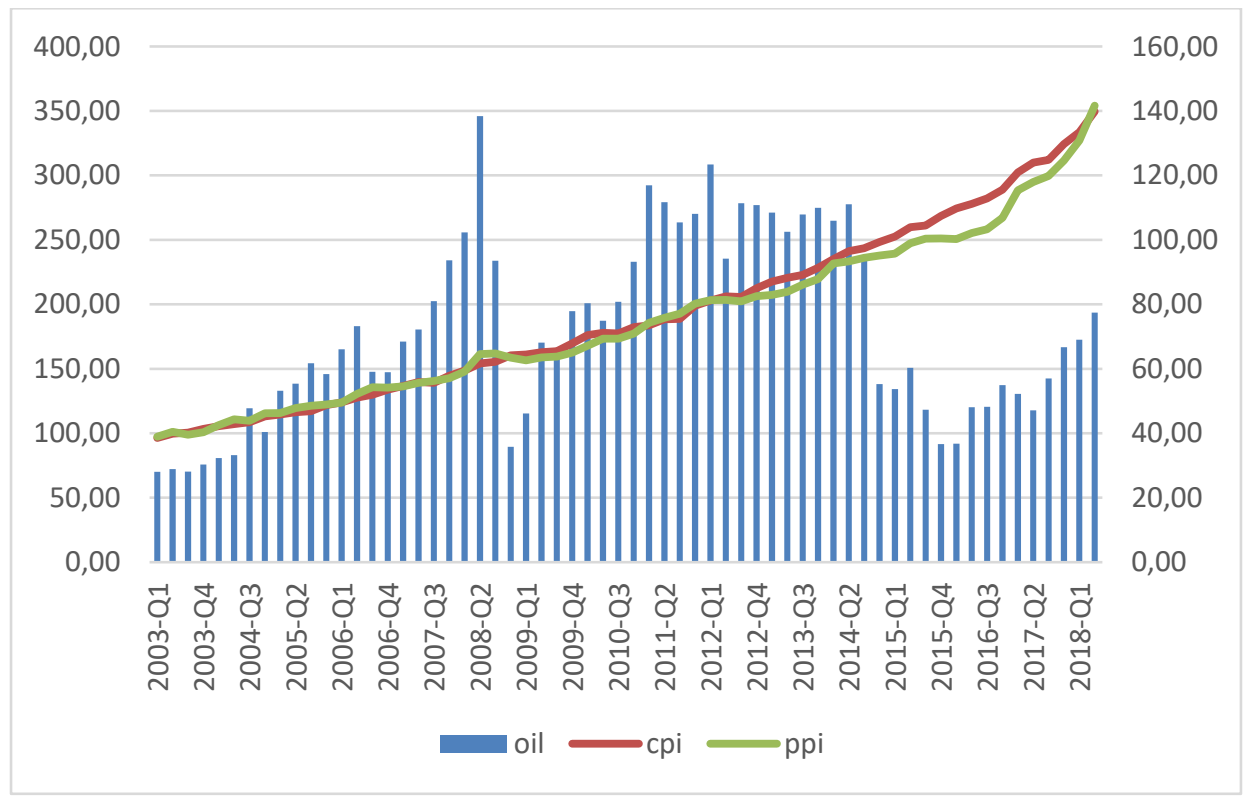

Şekil 1: Petrol Fiyatları ile Tüketici ve Üretici Fiyat Endeksleri

Kaynak: TCMB Elektronik Veri Dă̆ıtım Sistemi

Bu çalışmada Türkiye'de petrol fiyatlarından enflasyona bir geçişkenlik olup olmadığ 1 araştırılmaktadır. Petrol fiyatı geçişkenlik etkisi TÜFE ve ÜFE gibi yurt içi fiyat endekslerinde petrol fiyatlarındaki dalgalanmaların etkisine işaret etmektedir. $\mathrm{Bu}$ alandaki kapsamlı araştırmalar, küresel ham petrol fiyatlarının yerel enflasyon üzerindeki etkisinin çok net olmadığını göstermektedir. Petrol fiyatlarındaki artış doğrudan ve dolaylı olarak enflasyonu arttırırken, petrol fiyatlarındaki azalışın etkisi daha az olabilmektedir. Yani petrol fiyatlarının enflasyon üzerindeki etkisi asimetrik olabilir. $\mathrm{Bu}$ çalışmada Genişletilmiş Phillips eğrisi yaklaşımına dayanarak, doğrusal ve doğrusal olmayan ARDL yöntemleriyle dünya petrol fiyatlarındaki değişimlerin Türkiye'de tüketici ve üretici fiyatları üzerindeki etkisi incelenmektedir. 


\section{LITERATÜR}

Petrol fiyatlarındaki keskin ve kalıcı artışlar politika yapıcıların ve iktisatçıların ilgisini çekmiş ve petrol fiyatlarındaki şokların enflasyonist etkileri konusunda pek çok araştırma yapılmıştır. Petrol şoklarının ekonomik durgunluğa neden olup olmadığı konusunda görüş birliği olmamasına rağmen, petrol fiyatlarının en azından kısmen enflasyonu etkilediği genel kabul görmüş gerçeklerden birisidir. Petrol fiyatlarındaki artışların enflasyonist etkileri hakkında bilgi sahibi olmak, parasal otoritelerin bu şokları karşılamak için uygun politikaları benimsemesine yardımcı olacaktır. Chinn \& Leblanc (2004) petrol fiyatlarındaki değişimlerin enflasyona geçişini incelemişler ve ABD, Japonya ve Avrupa ülkelerinde petrol fiyatlarındaki artışların enflasyonu etkilediğini belirlemişlerdir. Choi, Furceri, Loungani, Mishra, \& Poplawski-Ribeiro (2017) 1970-2015 döneminde 72 gelişmiş ve gelişmekte olan ülke verisini kullanarak dünya petrol fiyatlarındaki dalgalanmaların yurtiçi enflasyona etkisini incelemişlerdir. Analiz sonuçlarına göre küresel petrol fiyatlarındaki \%10' luk artış yurtiçi enflasyon oranlarını ortalama olarak \%0,4 arttırmaktadır ve bu etki 2 yılın sonunda sone ermektedir. Ayrıca etkinin asimetrik olduğunu ve pozitif petrol fiyat şoklarının negatiflere göre etkisinin daya büyük olduğunu belirlemişlerdir.

Son dönemde yapılan çalışmalar petrol fiyatlarındaki artışların enflasyonist etkilerinin daha az olduğunu belgelemektedir. Yani, petrol fiyatlarındaki değişimler, 2000'lerde 1970'lerde olduğundan daha düşük bir enflasyona neden olmuştur. Chen (2009) 19 endüstri ülkesi ile yaptığı çalışmasında zamanla değişen petrol fiyatı geçişkenliği katsayısı elde etmiş ve yaklaşık tüm ülkelerde geçişkenliğin azaldığını belirlemiştir. Bunun nedenleri olarak yerel paraların değer kazanmasını, enflasyon karşısında aktif para politikaları uygulanmasını ve ticari açıklığın yüksek oranlara ulaşmasını göstermektedir. Blanchard \& Galí (2007) petrol fiyat şoklarının enflasyon ve ekonomik aktiviteler üzerindeki etkilerini 1983 öncesi ve sonrası dönem için VAR modeli kullanarak incelemişler ve petrol şoklarının dinamik etkilerinin azaldığını belirlemişlerdir. Bunun nedeni olarak petrol şoklarının yapısının değişmesini, üretimde petrolün daha az kullanılmasını, emek piyasasının daha esnek hale gelmesini ve para politikasındaki gelişmeleri göstermişlerdir. Hooker (2000) Phillips eğrisi yaklaşımını kullanarak yaptığı çalışmasında 1980'li yıllarda petrol fiyatındaki değişikliklerin enflasyonu ürünlerin fiyat endeksindeki doğrudan payları aracılığıyla etkilediğini ve çekirdek enflasyona herhangi bir etkisinin bulunmadığını, 1980 öncesinde ise petrol şoklarının çekirdek enflasyonu önemli ölçüde etkilediğini belirtmektedir.

Birçok çalışma da, küresel ham petrol fiyatlarının yurt içi fiyatlara olan aktarımının asimetrik ve doğrusal olmadığını ve küresel ham petrol fiyatlarının yükselmesinin ve düşüşünün yurt içi fiyatlara etkisinin farklı olduğunu teyit etmektedir. İlk olarak Mork (1989) ABD'de petrol fiyat değişikliklerine enflasyonun asimetrik ve doğrusal olmayan tepkilerini belirlemiştir. Daha sonra Hamilton \& Herrera (2004) benzer sonuçlar bularak petrol fiyatları ile ABD enflasyonu arasında doğrusal olmayan ve asimetrik ilişkiler bulunduğunu belirlemiştir. Long \& Liang (2018) ARDL ve NARDL modelleri kullanarak petrol fiyatlarındaki değişikliklerin Çin'in üretici ve tüketici fiyat endekslerine aktarımının uzun dönemde asimetrik olduğunu, petrol fiyatındaki artışların etkisinin, azalışın etkisine göre daha fazla olduğunu belirlemişlerdir. Bala \& Chin (2018) Cezayir, Angola, Libya ve Nijerya için yaptıkları çalışmada hem pozitif hem de negatif petrol fiyat değişimlerinin enflasyonu arttırdığını belirlemişlerdir. Ancak bu etki petrol fiyat düşüşlerinde daha anlamlı bulunmuştur. Lacheheb \& Sirag (2016) 1970-2014 döneminde Cezayir'de petrol fiyatları ile enflasyon oranları arasındaki ilişkiyi NARDL modeli kullanarak incelemişler ve petrol fiyat artışları ile enflasyon arasında anlamlı bir ilişki bulmuşlardır. Analiz sonuçlarına göre petrol fiyatındaki azalma ile enflasyon arasında ise anlamlı bir ilişki yoktur. Bu nedenle doğrusal ARDL modeli ile analizlerini sürdürüp petrol fiyat şokunun \%70'lik kısmının bir iki ay içerisinde sona ereceğini bulmuşlardır. Zhao, Zhang, Wang, \& Xu (2016) dinamik stokastik genel denge (DSGE) modeli kullanarak Çin'de petrol fiyat şoklarının çıtı ve enflasyon 
üzerindeki etkilerini incelemişlerdir. Politik olaylar sonucu gerçekleşen petrol arz şoklarının çıktı ve enflasyon üzerinde kısa dönem etkilerinin olduğunu, diğer şokların etkilerinin ise uzun dönemde görüldügünü belirlemişlerdir.

Türkiye ekonomisi için yapılan az sayıda çalışmada da diğer ülkelere benzer sonuçlar elde edilmiştir. Çatik \& Karaçuka (2012) Türkiye için farklı enflasyon düzeylerinde petrol fiyatlarından enflasyona geçişkenliği Markov Rejim Değişim modelini kullanarak analiz etmişler ve yüksek enflasyon rejiminden düşük enflasyon rejimine geçildiği dönemlerde işlenmiş petrol ürünleri fiyatlarından enflasyona geçişkenliğin önemli ölçüde düştüğ̈̈nü belirlemişlerdir. Öztürkler, Demir \& Yılmaz (2015) 2001-2015 döneminde Türkiye için NARDL modelini kullanarak yaptıkları çalışmada petrol fiyatlarının enflasyon üzerinde uzun dönemde etkisinin olduğunu kısa dönemde ise bir etkisinin bulunmadığını; ayrıca uzun dönemdeki etkinin simetrik olduğunu belirlemişlerdir. Dedeoğlu \& Kaya (2014) 1990-2012 dönemini kapsayan çalışmalarında petrol fiyatlarında yurtiçi fiyatlara aktarımda artış yönünde bir eğilim belirlemişlerdir. Bu artışın nedenini de nispi fiyatlardaki değişime bağlamışlardır. Genel maliyet yapısında petrol daha önemli hale geldiğinden firmalar petrol fiyatına daha duyarlı hale gelmektedir. Ayrıca petrol fiyatlarının üretici fiyatlarına etkisinin tüketici fiyatlarına etkisine göre iki kat fazla olduğu belirlenmiştir.

\section{YÖNTEM}

Phillips eğrisi enflasyon ve çıktı açığı arasındaki ilişkiyi incelemekte kullanılan en yaygın araçtır. Birçok akademik çalışmada Phillips eğrisine petrol fiyatları da dahil edilerek petrol fiyatlarının enflasyon üzerindeki etkileri incelenmiştir (Long \& Liang, 2018; Chen, 2009; Choi, Furceri, Loungani, Mishra, \& Poplawski-Ribeiro, 2017; Conflitti \& Luciani, 2017; Dedeoğlu \& Kaya, 2014; Öztürkler, Demir, \& Yılmaz, 2015). Bu çalışmada dünya petrol fiyatlarının Türkiye'de üretici fiyatları (PPI) ve tüketici fiyatları (CPI) üzerindeki asimetrik etkileri Genişletilmiş Phillips eğrisi çerçevesinde incelenecektir. Petrol fiyatlarının da dahil edildiği Genişletilmiş Phillips eğrisi (1) nolu eşitlikte verilmiştir.

$$
\pi_{t}=\beta(L) \pi_{t-1}+\gamma U G_{t}+\vartheta(L) o_{t}+\varepsilon_{t}
$$

Burada $\pi_{t}=p_{t}-p_{t-1}=\Delta p_{t}$ olup enflasyon oranın ifade etmektedir. Enflasyon oran üretici veya tüketici fiyatlarının logaritmasının birinci farkı alınarak hesaplanabilir. $U G$ işsizlik oranı ile doğal işsizlik oranı arasındaki açıktır. $o_{t}$ ise dünya piyasalarında belirlenen petrol fiyatını temsil etmektedir. Lgecikme operatörü, $\varepsilon_{t}$ ise bağımsız ve özdeş dağılmış hata terimidir. Okun kanununa göre işsizlik açığı yerine çıktı açığı kullanıldığında (1) nolu eşitlik yeniden düzenlenerek (2) nolu eşitlik elde edilir:

$$
\pi_{t}=\beta(L) \pi_{t-1}+\gamma\left(y_{t}-\tilde{y}_{t}\right)+\vartheta(L) o_{t}+\varepsilon_{t}
$$

Burada $y_{t}$ çıtı iken $\tilde{y}_{t}$ potansiyel çıktıyı ifade etmektedir. Dolayısıyla çıktı düzeyi ile potansiyel çıktı arasındaki fark $\left(y_{t}-\tilde{y}_{t}\right)$ çıktı açı̆̆ını verir. $y_{t}$ Gayrisafi yurtiçi Hasılanın logaritmas1 (lGDP), $\tilde{y}_{t}$ ise Hodrick-Prescott filtresi ile elde edilen trenddir. Hodrick-Prescott filtresi serinin kısa dönem dalgalanmalarını arıtarak doğrusal olmayan bir büyüme trendi oluşturma fonksiyonunu yerine getirmektedir ve elde edilen trend serisi potansiyel çıktı yerine kullanılmaktadır. (2) nolu eşitlikte $\pi_{t}$ yerine $\left(p_{t}-p_{t-1}\right)$ yazılırsa aşağıdaki (3) nolu eşitlik elde edilir: 


$$
p_{t}=\beta^{\prime}(L) p_{t-1}+\gamma\left(y_{t}-\tilde{y}_{t}\right)+\vartheta(L) o_{t}+\varepsilon_{t}
$$

(3) nolu eşitlik ile $p_{t}, o_{t}$ ve $\left(y_{t}-\tilde{y}_{t}\right)$ arasında uzun dönem denge ilişkisi elde edilebilir. Engle ve Granger tarafindan (Engle, 1982; Engle \& Granger, 1987) literatüre kazandırılan eşbütünleşme teorisine göre değişkenler düzeyde durağan olmasalar bile eşbütünleşik olabilirler ve aralarındaki dinamik ilişkiler hata düzeltme modeli (ECM) ile ortaya koyulabilir. Pesaran ve Shin (Pesaran, M. H., Shin, 1999) I(0) ve I(1) değişkenlerin birlikte yer alması durumunda değişkenlerin eşbütünleşik olabileceğini ve hata düzeltme modeline dayanan bir ARDL modeli ile ifade edilebileceğini belirtmişlerdir. Ancak değişkenlerin hiçbirisi I(2) olmamalıdır. ARDL modelinin tercih edilmesinin bir başka nedeni de küçük örneklemlerde bile güvenilir sonuçlar vermesidir. Dolayısıyla eğer fiyat düzeyi $(p)$, petrol fiyatları $(o)$ ve çıktı açığı $\mathrm{I}(0)$ ve $\mathrm{I}(1)$ koşulunu yerine getiriyorsa ve aralarında eşbütünleşme ilişkisi varsa, ARDL modeli (4) no'lu eşitlikteki gibi tahmin edilir.

$$
\pi_{t}=\Delta p=\alpha+\lambda_{1} p_{t-1}+\lambda_{2} o_{t-1}+\sum_{i=1}^{m-1} \vartheta_{i} \Delta p_{t-i}+\sum_{i=0}^{n-1} \tau_{i} \Delta o_{t-i}+\gamma\left(y_{t}-\tilde{y}_{t}\right)+\varepsilon_{t}
$$

$\Delta$ birinci fark işlemcisi olup petrol fiyatlarındaki ve fiyat düzeyindeki değişimleri göstermektedir. (4) numaralı model fiyat düzeyi ve petrol fiyatları arasındaki kısa ve uzun dönemdeki ilişkileri gösterebilir. Petrol fiyatlarından fiyat düzeyine geçişkenliği ölçen uzun dönem katsayısı $L_{\text {oil }}=\lambda_{2} / \lambda_{1}$ formülü ile hesaplanır. Ancak petrol fiyatlarındaki artış ve azalışların fiyat düzeyi üzerinde asimetrik ve doğrusal olmayan etkileri olabilir. Bu etkileri ortaya koyabilmek amaciyla Shin (Shin, Yu, \& Greenwood-Nimmo, 2013) doğrusal olmayan bir ARDL modeli (NARDL) geliştirmiştir. Bu çalışmada petrol fiyatlarından enflasyona asimetrik geçişkenliği araştırmak için kullanılacak NARDL modelinde petrol fiyatları pozitif $\left(o_{t}^{+}\right)$ve negatif $\left(o_{t}^{-}\right)$bileşenlerine ayrıştırılmıştır.

$$
\begin{aligned}
& o_{t}^{+}=\sum_{j=1}^{t} \Delta o_{j}^{+}=\sum_{j=1}^{t} \max \left(\Delta o_{j}, 0\right) \\
& o_{t}^{-}=\sum_{j=1}^{t} \Delta o_{j}^{-}=\sum_{j=1}^{t} \min \left(\Delta o_{j}, 0\right)
\end{aligned}
$$

Petrol fiyatlarının pozitif ve negatif bileşenleri de ilave edilerek (4) nolu simetrik $\operatorname{ARDL}(m, n)$ modelinden (5) nolu asimetrik $\operatorname{ARDL}(m, n)$ modeli elde edilir.

$$
\pi_{t}=\alpha+\lambda_{1} p_{t-1}+\lambda_{2} o_{t-1}^{+}+\lambda_{3} o_{t-1}^{-}+\sum_{i=1}^{m-1} \vartheta \Delta p_{t-i}+\sum_{i=0}^{n-1}\left(\tau_{t-1}^{+} \Delta o_{t-1}^{+}+\tau_{t-1}^{-} \Delta o_{t-1}^{-}\right)+\gamma\left(y_{t}-\tilde{y}_{t}\right)+\varepsilon_{t}
$$

Değişkenler arasında eşbütünleşme ilişkisi bulunup bulunmadığını test etmek için kullanılacak hipotezler şunlardır:

$$
\begin{array}{ll}
H_{0}: \lambda_{1}=\lambda_{2}=\lambda_{3}=0 \quad \text { (Değişkenler arasında eşbütünleşme ilişkisi yoktur) } \\
H_{1}: \lambda_{1} \neq \lambda_{2} \neq \lambda_{3} \neq 0 \quad \text { (Değişkenler arasında eşbütünleşme ilişkisi vardır) }
\end{array}
$$

Bu hipotezler Pesaran vd. (Pesaran, Shin, \& Smith, 2001) tarafından geliştirilen sınır testi için kullanılmaktadır. Sıfır hipotezinin reddedilmesi değişkenler arasındaki eşbütünleşme ilişkisinin varlığını ifade eder. Petrol fiyatlarındaki artış ve azalışların enflasyon üzerindeki uzun dönemdeki etkileri hesaplanacak uzun dönem etki katsayıları ile belirlenir. Petrol fiyatındaki 
artışların etkisini belirlemek için $L_{\text {oil }}=\lambda_{2} / \lambda_{1}$ katsayısı ve petrol fiyatlarındaki düşüşlerin etkisini belirlemek için $L_{\text {oil- }}=\lambda_{3} / \lambda_{1}$ katsayısı hesaplanır. Uzun dönem simetriyi test etmek için oluşturulması gereken hipotezler şunlardır:

$$
\begin{aligned}
& H_{0}: L_{o i l^{+}}=L_{o i l^{-}} \text {(Uzun dönem simetri) } \\
& H_{1}: L_{o i l^{+}} \neq L_{o i l^{-}}(\text {Uzun dönem asimetri) }
\end{aligned}
$$

İki katsayının birbirine eşit olup olmadığı standart wald testi ile test edilebilir.

Kısa dönem simetriyi test etmek için ise oluşturulması gereken hipotezler şunlardır:

$$
\begin{aligned}
& H_{0}: \sum_{i=0}^{n-1} \tau_{i}^{+}=\sum_{i=0}^{n-1} \tau_{i}^{-} \quad i=1,2, \ldots \ldots \ldots, n-1 . \quad \text { (K1sa dönem simetri) } \\
& H_{1}: \sum_{i=0}^{n-1} \tau_{i}^{+} \neq \sum_{i=0}^{n-1} \tau_{i}^{-} \quad i=1,2, \ldots \ldots \ldots, n-1 . \quad \text { (K1sa dönem asimetri) }
\end{aligned}
$$

NARDL modelinde kısa dönem veya uzun dönem (veya her ikisi birlikte) asimetrik ilişkiler belirlenirse, pozitif ve negatif dinamik çarpan etkileri aşağıdaki gibi hesaplanır:

$$
m_{h}^{+}=\sum_{j=0}^{h} \frac{\partial p_{t+j}}{\partial o_{t}^{+}} \text {ve } m_{h}^{-}=\sum_{j=0}^{h} \frac{\partial p_{t+j}}{\partial o_{t}^{-}}, \quad h=0,1,2 \ldots
$$

$h \rightarrow \infty$ ise $m_{h}^{+} \rightarrow L_{\text {oil }}^{+}$ve $m_{h}^{-} \rightarrow L_{\text {oil }}^{-}$olur. Daha önce belirtildiği gibi $L_{\text {oil }}^{+}$ve $L_{\text {oil }}^{-}$uzun dönem etki katsayılarıdır.

\section{BULGULAR}

Analizde 2003 yılının 1. çeyreği ile 2018 yılının 2. çeyreği arasındaki çeyrek dönemlik veriler kullanılmıştır. Fiyat değişkenleri olan üretici fiyat endeksi (PPI), tüketici fiyat endeksi (CPI) ve petrol fiyatları doğal logaritmaları alınarak kullanılmıştır (lppi, lcpi, loil). Petrol fiyatlarını temsil etmek için Avrupa Brent Petrolünün varil başına fiyatı (\$) kullanılmıştır. Tüketici ve üretici fiyat endeksleri 2003 baz yıllı serilerdir. Tüm veriler Türkiye Cumhuriyet Merkez Bankası Elektronik Veri Dağıtım Sisteminden elde edilmiştir. Çıktı açığını hesaplayabilmek için öncelikle GDP serisinin doğal logaritması alınmış ve Tramo/Seats yöntemi kullanılarak mevsimsellikten arındırılmıştır. Daha sonra Hodrick-Prescott filtresi ile elde edilen trend potansiyel GDP'yi temsil etmek üzere kullanılmış ve GDP ile potansiyel GDP arasındaki fark hesaplanarak $\left(y_{t}-\tilde{y}_{t}\right)$ çıktı açı̆̆ı elde edilmiştir.

\subsection{Birim Kök Testleri}

Öncelikle serilerin bütünleşme derecelerini öğrenmek için Augmented Dickey Fuller (ADF) ve Phillips-Perron (PP) birim kök testleri uygulanmıştır. Testlerin sonuçları Tablo 1'de yer almaktadir. 
Tablo 1: ADF ve PP Birim Kök Testleri

\begin{tabular}{|l|l|c|c|c|c|}
\hline & \multicolumn{2}{|c}{ Değişkenler } & \multicolumn{2}{c}{ Düzey } & \multicolumn{2}{c|}{ 1. Fark } \\
\hline Test & \multicolumn{2}{c|}{ ADF } & PP & ADF & PP \\
\cline { 2 - 6 } İstatistiği & lppi & $-2,094(0,53)$ & $-1,93(0,62)$ & $-6,34^{*}(0,00)$ & $-6,17 *(0,00)$ \\
(Sabitli ve & lcpi & $-1,55(0,79)$ & $-2,87(0,17)$ & $-0,203(0,99)$ & $-14,65(0,00)^{*}$ \\
Trendli) & Loil & $-2,38(0,38)$ & $-2,31(0,41)$ & $-7,01(0,00)^{*}$ & $-7,30(0,00)^{*}$ \\
& Gap & $-2,95(0,15)$ & $-2,97(0,14)$ & $-8,48(0,00)^{*}$ & $-8,48(0,00)^{*}$ \\
\hline
\end{tabular}

Parantez içindeki değerler olasılık (Prob) değerleridir. Gecikme uzunluğunun seçiminde Schwarz Bilgi Kriteri (SIC) kullanılmıştır. Bant genişliği ise Bartlett Kernel modeli kullanılarak Newey West'e göre belirlenmiştir. * \% 1 anlam düzeyinde anlamlılığ 1 ifade etmektedir.

PP testi sonuçlarına göre tüm seriler I(1) olarak belirlenmiştir. ADF testi sonuçlarına göre ise lcpi serisi dışındaki seriler I(1) dir. lcpi serisi için ADF ve PP testleri çelişkili sonuçlar vermektedir. Bu çelişikinin nedeni serideki yapısal kırılmalar olabilmektedir. Bu nedenle lcpi serisine yapısal kırılmalı birim kök testi uygulanarak tablo 2'deki sonuçlar elde edilmiştir.

Tablo 2: Kırılmalı Birim Kök Testi Sonuçları

\begin{tabular}{|l|l|l|l|l|l|}
\hline & Değişken & Düzey & Prob & 1. Fark & Prob \\
\hline $\begin{array}{l}\text { Test İstatistiği } \\
\text { (Sabitli\&Trendli) }\end{array}$ & $\begin{array}{l}\text { Lcpi } \\
\text { Kırılma Tarihi 2016Q4 }\end{array}$ & $-0,91$ & $>0,99$ & $-9,48^{*}$ & $<0,01$ \\
\cline { 4 - 6 } & & & & \\
\hline
\end{tabular}

Kırılmalı birim kök testi sonuçlarına göre lcpi serisi düzeyde durağan değilken birinci farlı alındığında durağan hale gelmektedir. Bu nedenle lcpi serisinin de diğer seriler gibi I(1) olduğu sonucuna ulaşılmıştır. Hiçbir değişkenin I(2) olmadığı belirlendikten sonra simetrik ve asimetrik modeller tahmin edilmiştir. Yurtiçi fiyatları temsil etmek üzere üretici fiyat endeksi (PPI 2003=100) ve tüketici fiyat endeksi (CPI 2003=100) kullanılmış ve petrol fiyatlarındaki dalgalanmaların enflasyon üzerindeki simetrik ve asimetrik etkileri ARDL ve NARDL modelleri kullanılarak araştırılmıştır.

\subsection{Petrol Fiyatlarının Tüketici Fiyatlarına Etkisi}

Öncelikle petrol fiyatlarındaki değişimin tüketici fiyatları üzerindeki etkisi ARDL modeli ile incelenmiştir. Uygun modelin belirlenmesinde Akaike Bilgi Kriteri (AIC) kullanılmıştır. Bu kritere göre ARDL $(4,4,1)$ modeli seçilerek LCPI'nin 4, LOIL'in 4 ve GAP'in 1 gecikmesi modele dâhil edilmiştir.

Petrol fiyatları ve tüketici fiyatları arasındaki uzun dönem ilişkinin varlığını araştırmak için yapılan sınır testi sonuçları tablo 3 'te verilmektedir. Buna göre hesaplanan $F_{P S S}$ istatistiğinin örnek değeri olan 20,44; tablo üst sınır değeri olan 5'ten (\%5 anlam düzeyi) büyük olduğundan, Türkiye'de petrol fiyatları ve tüketici fiyatları arasında eşbütünleşme ilişkisinin varllğ 1 tespit edilir. 
Tablo 3: Eşbütünleşme İçin Sınır Testi Sonuçları

\begin{tabular}{|lll|}
\hline Hesaplanan $F_{P S S}$ istatistiği: 20,44 & \multicolumn{1}{c|}{$\underline{\text { Kritik Değerler }}$} \\
\hline & Alt Sınır $I(0)$ & Üst Sınır I(1) \\
$\% 1$ anlam düzeyi & 4,13 & 5,00 \\
$\% 5$ anlam düzeyi & 3,10 & 3,87 \\
$\% 10$ anlam düzeyi & 2,63 & 3,35 \\
\hline
\end{tabular}

ARDL $(4,4,1)$ modeline ait uzun dönem katsayılar belirlenmiş ve sonuçlar Tablo 4'te verilmiştir. Buna göre petrol fiyatlarının tahmin edilen katsayısı pozitif ve olasılık değeri (prob $=0,0908$ ) hesaplandığından \%10 anlam düzeyinde anlamlıdır. Yani petrol fiyatlarındaki dalgalanmalar uzun dönemde tüketici fiyatlarını etkilemektedir. Yapılan tanısal testlerin sonuçlarına göre modelde otokorelasyon, değişen varyans ve belirleme hatası sorunları bulunmamaktadır. Ayrıca modelden elde edilen artık terimler normal dağılıma sahiptir.

Tablo 4: ARDL(4,4,1) Modeline Ait Uzun Dönem Katsayılar ve Tanısal Testler

\begin{tabular}{llll}
\multicolumn{2}{l}{ Bağımlı Değişken: LCPI } & & \\
\hline Değişkenler & Katsayılar & t istatistiği & Prob. Değeri \\
\hline LOIL & 0,8122 & 1,7275 & 0,0908 \\
GAP & $-9,6556$ & $-1,6189$ & 0,1123 \\
Sabit & $-2,9825$ & 3,6003 & 0,4117 \\
\hline
\end{tabular}

Tanisal Testler

Otokorelasyon LM Testi $=3,1104(0,2111)$

Değişen Varyans White Testi $=8,84(0,6358)$

Ramsey RESET Testi= 3,54 (0,2456)

JB Normallik Testi=0,32 (0,8497)

Petrol fiyatları ile tüketici fiyatları arasındaki asimetrik ilişkileri incelemek amacıyla doğrusal olmayan NARDL modeli tahmin edilerek sonuçlar Tablo 5'te verilmiştir. 
Tablo 5: NARDL Modeli Tahmin Sonuçları

\begin{tabular}{|c|c|c|}
\hline \multicolumn{3}{|c|}{ Bağımlı Değişken $\triangle L C P I$} \\
\hline Değişken & Katsayı & $\mathrm{t}$ istatistiği \\
\hline$C$ & $-0,497 * *$ & $-2,549(0,0146)$ \\
\hline$L C P I_{t-1}$ & $0,118^{*}$ & $2,755(0,008)$ \\
\hline$L_{O I L}^{+}$ & $-0,015^{*}$ & $-2,727(0,009)$ \\
\hline$L_{O I L}^{-}$ & 0,013 & $1,524(0,135)$ \\
\hline GAP & $-0,033$ & $-0,456(0,650)$ \\
\hline$\Delta L C P I_{t-1}$ & $-0,517 *$ & $-3,740(0,000)$ \\
\hline$\Delta L C P I_{t-2}$ & $-0,528^{*}$ & $-3,804(0,000)$ \\
\hline$\Delta L C P I_{t-3}$ & $-0,542^{*}$ & $-4,157(0,000)$ \\
\hline$\Delta L O I L_{t}^{+}$ & $-0,011$ & $-0,624(0,535)$ \\
\hline$\Delta L O I L_{t-1}^{+}$ & 0,015 & $0,825(0,413)$ \\
\hline$\Delta L O I L_{t-2}^{+}$ & 0,001 & $0,119(0,905)$ \\
\hline$\Delta L O I L_{t-3}^{+}$ & $0,035^{* *}$ & $2,112(0,040)$ \\
\hline$\Delta L O I L_{t}^{-}$ & $-0,006$ & $-0,498(0,621)$ \\
\hline$\Delta L O I L_{t-1}^{-}$ & 0,010 & $0,895(0,376)$ \\
\hline$\Delta L O I L_{t-2}^{-}$ & 0,001 & $0,131(0,896)$ \\
\hline$\Delta L O I L_{t-3}^{-}$ & $0,022 * * *$ & $1,963(0,056)$ \\
\hline Breusch Gc & & $0,05(0,816)$ \\
\hline Jarque Berc & & $3,827(0,171)$ \\
\hline
\end{tabular}

*\%1 **\%5 ***\%10 anlam düzeyinde anlamlılı̆̆ ifade etmektedir. Parantez içindeki değerler Prob değerleridir. 
NARDL modelinden sınır testi yapmak için hesaplanan $F_{P S S}$ değeri 13,00 olup \%1 anlam düzeyindeki üst sınır değerinden büyüktür. Buna göre petrol fiyatları ile tüketici fiyatları arasında bir eşbütünleşme ilişkisi vardır. Tahmin edilen modelden elde edilen uzun dönem katsayılar tablo 6'da sunulmaktadır.

Tablo 6: NARDL Modeline Ait Uzun Dönem Katsayılar

\begin{tabular}{llll}
\hline Bağımlı Değişken: LCPI & & \\
\hline Değişkenler & Katsayılar & t istatistiği & Prob. Değeri \\
\hline LOIL $^{+}$ & $0,1305^{*}$ & 3,4474 & 0,0013 \\
LOIL $^{-}$ & $-0,1127^{*}$ & $-2,5971$ & 0,0130 \\
GAP & 0,2811 & 0,5048 & 0,6163 \\
$C$ & $4,2090^{*}$ & 29,2906 & 0,0000
\end{tabular}

* \%1 anlam düzeyinde anlamlılı̆̆ 1 ifade etmektedir.

Petrol fiyatlarındaki artış ve azalışların uzun dönemde CPI üzerindeki etkilerini gösteren $\mathrm{LOIL}^{+}$ve $\mathrm{LOIL}^{-}$değişkenlerine ait katsayılar istatistiksel olarak anlamlıdır. Dünya petrol fiyatlarındaki \%100'lük bir artış sonucunda yurtiçi tüketici fiyat endeksi (CPI) \%13,05 artarken, petrol fiyatlarındaki \%100'lük bir azalış tüketici fiyat endeksini \%11,27 azaltmaktadır.

Uzun dönem asimetriyi araştırmak amaciyla $H_{0}: L_{o i l^{+}}=L_{o i l^{-}}$hipotezi test edilir. Hesaplanan Wald $_{L R}=302,46$ olup Prob=0,000 bulunmuştur. Buna göre sifır hipotezi reddedildiğinden petrol fiyatlarının tüketici fiyatları üzerinde uzun dönemde asimetrik etkileri bulunmaktadır. Kısa dönem asimetriyi araştırmak amaciyla $H_{0}: \sum_{i=0}^{n-1} \tau_{i}^{+}=\sum_{i=0}^{n-1} \tau_{i}^{-} \quad i=1,2, \ldots \ldots \ldots ., n-1$. hipotezi test edilir. Hesaplanan Wald $_{S R}=0,079$ olup Prob=0,7795 bulunmuştur. Bu sonuçlara göre sıfir hipotezi reddedilmez ve petrol fiyatlarının tüketici fiyatları üzerindeki etkisi kısa dönemde simetriktir.

\subsection{Petrol Fiyatlarının Üretici Fiyatlarına Etkisi}

Petrol fiyatlarındaki dalgalanmaların üretici fiyat endeksi üzerindeki etkilerini belirlemek amacıyla benzer analizler petrol fiyatları ile üretici fiyatları arasında da yapılmıştır. Eşbütünleşmenin araştırıldığı sınır testi sonuçları tablo 7'de verilmektedir. Hesaplanan $F_{P S S}$ istatistiği \%1 anlam düzeyindeki üst sınır değerinden yüksek olduğundan sıfir hipotezi reddedilir ve petrol fiyatları ile üretici fiyat endeksi arasında bir eşbütünleşme ilişkisi bulunduğu sonucuna ulaşılır. 
Tablo 7: Sınır Testi Sonuçları

\begin{tabular}{|c|c|c|}
\hline Hesaplanan $F_{P S S}$ istatistiği: 15,22 & $\underline{\text { Kritik Dĕğerler }}$ & \\
\hline & Alt Sinir $I(0)$ & Üst Sınır I(1) \\
\hline$\% 1$ anlam düzeyi & 4,13 & 5,00 \\
\hline$\% 5$ anlam düzeyi & 3,10 & 3,87 \\
\hline \%10 anlam düzeyi & 2,63 & 3,35 \\
\hline
\end{tabular}

Tahmin edilen ARDL $(1,2,0)$ modeline ait uzun dönem katsayılar ve tanısal testler Tablo 8'de sunulmaktadır.

Tablo 8: ARDL $(1,2,0)$ Modeline Ait Uzun Dönem Katsayılar ve Tanısal Testler

Bağımlı Değişken: LPPI

\begin{tabular}{llll}
\hline Değişkenler & Katsayılar & t istatistiği & Prob. Değeri \\
\hline LOIL & 092811 & 0,1968 & 0,8447 \\
GAP & $-6,28155$ & $-1,0140$ & 0,3151 \\
Sabit & 3,51058 & 1,79019 & 0,0790 \\
\hline
\end{tabular}

\section{Tanısal Testler}

Otokorelasyon LM Testi $=4,0820(0,1299)$

Değişen Varyans White Testi $=4,41(0,4909)$

Ramsey RESET Testi $=4,56(0,3542)$

JB Normallik Testi=2,64 $(0,2685)$

Modelde otokorelasyon, değişen varyans ve belirleme hatası sorunları yoktur. Petrol fiyatlarının uzun dönemde üretici fiyatları üzerindeki etkisini belirleyen katsayı pozitif olmasına rağmen istatistiksel olarak anlamlı değildir. 
Tablo 9: NARDL Modeli Tahmin Sonuçları

\begin{tabular}{|c|c|c|}
\hline \multicolumn{3}{|c|}{ Bağımlı Değişken $\triangle L P P I$} \\
\hline Değişken & Katsay 1 & t istatistiği \\
\hline$C$ & $-0,322$ & $-1,1244(0,266)$ \\
\hline$L P P I_{t-1}$ & 0,0754 & $1,2162(0,2294)$ \\
\hline$L_{O I L}^{+}$ & $-0,0111$ & $-1,1063(0,2737)$ \\
\hline$L O I L_{t-1}^{-}$ & 0,0054 & $0,4703(0,6401)$ \\
\hline GAP & $-0,049$ & $-0,4271(0,6710)$ \\
\hline$\Delta L O I L_{t}^{-}$ & $0,0399 * * *$ & $1,8930(0,0639)$ \\
\hline$\Delta L O I L_{t-1}^{-}$ & $0,0582 *$ & $3,1671(0,0026)$ \\
\hline \multicolumn{3}{|c|}{ Breusch Godfrey LM 3,4570 $(0,1775) \quad$ White $3,6739(0,7207)$} \\
\hline Jarque Ber & \multicolumn{2}{|c|}{ RESET 3,462 $(0,265)$} \\
\hline
\end{tabular}

NARDL modelinden sınır testi yapmak için hesaplanan $F_{P S S}$ değeri 17,16 olup \%1 anlam düzeyindeki üst sınır değerinden büyüktür. Buna göre petrol fiyatları ile üretici fiyatları arasında bir eşbütünleşme ilişkisi vardır. Tahmin edilen modelden elde edilen uzun dönem katsayılar tablo 10 'da sunulmaktadır.

Tablo 10: NARDL Modeline Ait Uzun Dönem Katsayılar

\begin{tabular}{llll}
\hline Bağımlı Değişken: LPPI & & \\
\hline Değişkenler & Katsayılar & t istatistiği & Prob. Değeri \\
\hline LOIL $^{+}$ & 0,1474 & 1,4242 & 0,1604 \\
OOIL $^{-}$ & $-0,0724$ & $-0,6138$ & 0,5420 \\
$G A P$ & 0,6615 & 0,5216 & 0,6041 \\
$C$ & 4,2746 & 13,9836 & 0,0000 \\
\hline
\end{tabular}

Petrol fiyatlarındaki artışlar uzun dönemde üretici fiyatlarını arttırırken, petrol fiyatlarındaki azalışlar ise üretici fiyatlarını düşürmektedir. Sayısal olarak ifade edilirse, petrol 
fiyatlarındaki \%100 lük artış üretici fiyatlarını \%14,7 arttırırken, petrol fiyatlarındaki $\% 100$ azalış üretici fiyatlarını \%7,24 düşürmektedir. Bu sonuçlar asimetrik etkinin varlığını açıkça göstermektedir. Ancak bu etkiler istatistiksel olarak anlamlı değildir. Uzun dönem asimetriyi araştırmak amacıyla hesaplanan Wald $_{L R}=39,25$ olup Prob=0,000 bulunmuştur. Buna göre petrol fiyatlarının üretici fiyatları üzerinde uzun dönemde asimetrik etkileri bulunmaktadır. Kısa dönem asimetriyi araştırmak amaciyla hesaplanan Wald $_{S R}=0,3768$ olup Prob $=0,5420$ bulunmuştur. $\mathrm{Bu}$ sonuçlara göre petrol fiyatlarının üretici fiyatları üzerindeki etkisi kısa dönemde simetriktir.

\section{SONUÇ}

$\mathrm{Bu}$ çalışmada Genişletilmiş Phillips eğrisi yaklaşımına dayanarak, doğrusal ve doğrusal olmayan ARDL yöntemleriyle dünya petrol fiyatlarındaki değişimlerin Türkiye'de tüketici ve üretici fiyatları üzerindeki asimetrik etkisi incelenmiştir. Elde edilen sonuçlara göre petrol fiyatlarındaki dalgalanmaların tüketici ve üretici fiyatları üzerindeki etkisi uzun dönemde asimetrikken, kısa dönemde ise simetriktir. Dünya petrol fiyatlarındaki \%100'lük bir artış sonucunda yurtiçi tüketici fiyat endeksi (CPI) \%13,05 üretici fiyat endeksi (PPI) \%14,7 artmaktadır. Tüketici fiyatlarındaki artış; ilk aşamada akaryakıt, doğalgaz gibi tüketicilerin doğrudan kullandıkları ürünlerin fiyatlarının artması sonucunda gerçekleşir. İkinci aşama ise petrol fiyatlarındaki artışın üretim maliyetlerini arttırması ve artan maliyetlerin fiyat artışları olarak tüketiciye yansıtılmasıdır. Uzun dönemde üretici fiyat endeksindeki artışın daha fazla olması üreticilerin maliyetten kaynaklanan artışların tamamını, talep yetersizliği ya da durgunluk gibi nedenlerle tüketiciye yansıtamadıklarını göstermektedir. Tüketici fiyatlarının daha az artmasının bir başka nedeni de enflasyonu önlemek amacıyla devletin akaryakıt üzerinden aldığı vergilerin bir bölümünden vazgeçerek petrol fiyat artışlarının tamamını tüketicinin doğrudan kullandığı petrol yan ürünleri üzerine yansitmamasıdır.

Arz ve talep koşulları nedeniyle bazı dönemlerde dünya petrol fiyatlarında düşüşler de yaşanmaktadır. Petrol fiyatlarının düşmesi de doğrudan tüketicilerin kullandıkları petrol yan ürünleri ve maliyetler aracılığıyla tüketici ve üretici fiyatlarını etkilemektedir. Kullandığı petrolün büyük bölümünü ithal etmek durumunda olan Türkiye için dünya petrol fiyatlarının düşük seyretmesi ekonomik dengeleri sağlamak için büyük bir avantajdır. Analiz sonuçlarına göre petrol fiyatlarındaki \%100'lük bir azalış tüketici fiyat endeksini $\% 11,27$, üretici fiyat endeksini \%7,24 azaltmaktadır. Petrol fiyatlarındaki azalış ulaşım, ısınma gibi tüketici bütçesinde önemli yer tutan kalemleri etkileyerek tüketici fiyatlarını, üretici fiyatlarına göre daha fazla etkilemektedir.

Petrol fiyat artışlarının dolaylı etkisi ise enflasyon beklentilerini etkileyerek gerçekleşir. Geçmiş dönem enflasyon şoklarının neden olduğu reel gelir kayıpları ekonomik birimlerin enflasyon beklentilerini etkileyerek daha yüksek fiyat ve ücret belirleme davranışına neden olur. Bu tür dolaylı etkilerin olabilmesi ekonomik konjonktürün durumu, mal ve hizmet piyasasının esnekliği, enflasyon beklentilerinin nasıl oluştuğu, Merkez Bankasının güvenilirliği gibi birçok değişik faktöre bağlıdır. Petrol fiyatlarındaki değişimin en fazla ve en hızlı etkisi ise doğrudan tüketicilerin kullandıkları petrol ve yan ürünlerinin fiyatlarındaki değişikliklerde görülür. Petrol ithalatçısı bir ülke olan Türkiye'nin bu ilk etkileri ortadan kaldırmak konusunda yapabileceği çok fazla şey bulunmamaktadır. İthal edilen petrol miktarını azaltmak amacıyla arz tarafında yeni petrol rezervleri aranabilir, talep tarafinda alternatif yenilenebilir enerji kaynakları kullanılabilir ve enerji daha verimli kullanılarak petrol talebi azaltılabilir. Bu çalışma sonuçları petrol fiyatlarının uzun dönemde tüketici ve üretici fiyatlarını asimetrik olarak etkilediğini göstermektedir. Türkiye petrol ithalatçısı bir ülke olarak dünya petrol fiyatlarını etkileyemez 
ancak inandırıcı bir para politikası ile enflasyon beklentilerini iyi yönetip petrol fiyatlarındaki artışların enflasyona geçişlerini orta ve uzun vadede azaltabilir.

\section{KAYNAKÇA}

Bala, U., \& Chin, L. (2018). Asymmetric Impacts of Oil Price on Inflation : An Empirical Study of African OPEC Member Countries, (August). https://doi.org/10.20944/preprints201808.0064.v1

Blanchard, O. J., \& Galí, J. (2007). The Macroeconomic Effects of Oil Price Shocks: Why are the 2000s so different from the 1970s? NBER Chapters. https://doi.org/10.1017/CBO9781107415324.004

Çatik, A. N., \& Karaçuka, M. (2012). Oil pass-through to domestic prices in Turkey: Does the change in inflation regime matter? Ekonomska Istrazivanja, 25(2), 277-296. https://doi.org/10.1080/1331677X.2012.11517508

Chen, S. S. (2009). Oil price pass-through into inflation. Energy Economics. https://doi.org/10.1016/j.eneco.2008.08.006

Chinn, M., \& Leblanc, M. (2004). Do High Oil Prices Presage Inflation? Business Economics. https://doi.org/4aabcd045a8ec14c0d08ecd330968821

Choi, B. S., Furceri, D., Loungani, P., Mishra, S., \& Poplawski-Ribeiro, M. (2017). Oil Prices and Inflation Dynamics: Evidence from Advanced and Developing Economies. IMF Working Paper, 55.

Conflitti, C., \& Luciani, M. (2017). Oil Price Pass-Through into Core Inflation. Ssrn. https://doi.org/10.2139/ssrn.3082191

Dedeoğlu, D., \& Kaya, H. (2014). Pass-through of oil prices to domestic prices: Evidence from an oil-hungry but oilpoor emerging market. Economic Modelling, 43(February 2001), 67-74. https://doi.org/10.1016/j.econmod.2014.07.038

ECB. (2010). Oil Prices - Their Determinants and Impact on Euro Area Inflation and the Macroeconomy. Monthly Bulletin, (August), 75-92.

Engle, R. F. (1982). Autoregressive Conditional Heteroscedasticity with Estimates of the Variance of United Kingdom Inflation. Econometrica. https://doi.org/10.2307/1912773

Engle, R. F., \& Granger, C. W. J. (1987). Co-Integration and Error Correction: Representation, Estimation, and Testing. Econometrica, 55(2), 251. https://doi.org/10.2307/1913236

Hamilton, J. D., \& Herrera, A. M. (2004). Oil Shocks and Aggregate Macroeconomic Behavior: The Role of Monetary Policy: A Comment. Journal of Money, Credit, and Banking. https://doi.org/10.1353/mcb.2004.0012

Hooker, M. A. (2000). Are Oil Shocks Inflationary? Asymmetric and Nonlinear Specifications Versus Changes in Regime. Ssrn. https://doi.org/10.2139/ssrn.208890

Lacheheb, M., \& Sirag, A. (2016). Oil Price and inflation in Algeria : A nonlinear ARDL approach. Topics in Middle Eastern and African Economics, 18(2), 45-60.

Long, S., \& Liang, J. (2018). Asymmetric and nonlinear pass-through of global crude oil price to China's PPI and CPI $\begin{array}{llll}\text { inflation. } & \text { Economic } & \text { Research-Ekonomska } & \text { Istrazivanja, } \\ \end{array}$ https://doi.org/10.1080/1331677X.2018.1429292

Mork, K. A. (1989). Oil and the Macroeconomy When Prices Go Up and Down: An Extension of Hamilton's Results. Journal of Political Economy. https://doi.org/10.1086/261625

Öztürkler, H., Demir, F., \& Y1lmaz, S. (2015). Crude Oil Price Pass-Through to Domestic Prices in Turkey: Asymmetric Nonlinear ARDL Approach. EY International Congress on Economics II, (256), 1-14.

Pesaran, M. H., Shin, Y. (1999). An autoregressive distributed lag modelling approach to cointegration analysis. In Econometrics and Economic Theory in the 20th Century: The Ragnar Frisch Centennial Symposium. (pp. 1-31). https://doi.org/10.1017/CCOL521633230

Pesaran, M. H., Shin, Y., \& Smith, R. J. (2001). Bounds testing approaches to the analysis of level relationships. Journal of Applied Econometrics, 16(3), 289-326. https://doi.org/10.1002/jae.616 
Optimum Journal of Economics and Management Sciences, Vo1. 6, No. 1- http://dergipark.gov.trloptimum/ Özata-Asymmetric and Nonlinear Pass-Through of Global Crude Oil Price to Inflation in Turkey

Shin, Y., Yu, B., \& Greenwood-Nimmo, M. (2013). Modelling Asymmetric Cointegration and Dynamic Multipliers in a Nonlinear ARDL Framework. SSRN. https://doi.org/10.2139/ssrn.1807745

Zhao, L., Zhang, X., Wang, S., \& Xu, S. (2016). The effects of oil price shocks on output and inflation in China. Energy Economics, 53, 101-110. https://doi.org/10.1016/j.eneco.2014.11.017 